\title{
PSYCHOLOGICAL WELL-BEING AS PREDICTOR OF MARITAL STABILITY AMONG EMPLOYED WOMEN IN LAGOS STATE, NIGERIA
}

\author{
Mrs. Okojide, A. C. ${ }^{1 \star}$, Prof. Adekeye, O. A. ${ }^{2 \star} \&$ Dr. Adejumo, G. O. ${ }^{3}$ \\ 1, 2, 3 Department of Psychology, Covenant University, Ota, Ogun State, Nigeria \\ angela.okojide@stu.cu.edu.ng, jide.adekeye@covenantuniversity.edu.ng, \\ gbadebo.adejumo@covenantuniversity.edu.ng \\ ${ }^{*}$ Corresponding author
}

\begin{abstract}
Marital stability is an essential factor in strengthening the family relationship, societal growth and sustainable national development. The institution of marriage is experiencing global instability, which is a threat to family life. Several factors have been identified as predictors of marital stability. While some have been empirically tested, some are mere theoretical postulations. Therefore, this study examined the extent to which psychological well-being predicts marital stability among women in Lagos State, Nigeria. The study employed a descriptive survey design. A total of 540 married female secondary school teachers and married female commercial bank workers were randomly selected for the study. Data was collected using questionnaire titles "Psychological Well-Being and Marital Stability Scales." One research question and two research hypotheses were raised. The research questions were answered using descriptive statistics while the hypotheses were tested at the $p=0.05$ level of significance, using inferential statistics. Simple linear regression analysis was used to test hypothesis one while independent sample t-test for hypothesis two. The results revealed a high prevalence of psychological well-being among women teachers and bankers and a significant influence of psychological well-being on marital stability $\left(R=.184, R^{2}=0.034, F=3.104, p=0.005\right.$. Furthermore, no significant difference was found in the marital stability of married female teachers and bankers. Based on the findings, recommendations were made. The study concluded that positive relations with others as an indicator of psychological well-being were positively related to marital stability. Also, participants' marital stability could be explained by different coping strategies, which the women in the two sub-sectors had devised to manage their work roles and family responsibilities.
\end{abstract}

Keywords: marital stability, predictors, psychological well-being, women.

\section{INTRODUCTION}

Marriage is the most essential and fundamental human relationship. It provides a basic structure that establishes a family relationship and raises the next generation (Nadar, 2018). Marriage is defined in this study as a close and intimate relationship between a man and a woman as husband and wife. Cumming, Marrilee and George (2010) described marriage as a deliberate intimate relationship integrally ordered to procreation and sharing of family life, which calls for permanence and exclusive commitment in whatever way the couple decides. A good and stable marriage is a marital relationship based on love, mutual respect and the couple's satisfaction with the relationship (Karney \& Bradbury, 2020). A Stable marriage makes way 
for a healthy and happy life and provides the necessary condition for having and nurturing responsible children (Kamp-Dush, Rhoades, Sandberg-Thoma \& Schoppe-Sullivan, 2014). However, marriage becomes unstable when couples cannot manage conflicting issues that arise in the union. Approaches used by couples to handle marital challenges positively or negatively influence the intimate life (Shakarami, Zahrakar \& Mohsenzadeh, 2016). Several factors have been identified as predictors of marital stability. They include but are not limited to education, age of marriage, employment status, physical health, and psychological wellbeing (Adejori, Okolie, Musa \& Shehu, 2019). The life of human beings consists of both physical and mental states. Therefore, an individual's health and well-being are dependent on the inter-relationship between the psychological and physical state. (Kolappa, Henderson \& Kishore, 2013). Scholars have proposed that marriage promotes general well-being and that psychological well-being promotes marital stability, giving a bi-directional relationship (Hazarika, 2019; Shmerling, 2016).

\subsection{Statement of the Problem}

In our contemporary society, marital instability has become a common social issue associated with separation, divorce and widowhood (Amina, 2008). There is a high prevalence of depression and anxiety among women than men (Whiteford, Degenhart, Rehm, Baxter, Ferrari, Erskine, Charlson, et al., 2013; World Health Organisation, 2020). Eaton, Kann, Kinchen, Shanklin, Flint, and Hawkince (2012) also indicated that women are prone to mood and anxiety disorders. Comez-Ikican et al. (2020) reported that women who suffer depressive symptoms show decreased marital satisfaction and experience challenges with sexual function. Studies have indicated that marital stability affects psychological well-being. It is common in the literature, but can the psychological well-being of individuals affect their marital stability? This study aims to investigate if psychological well-being influences marital stability.

\subsection{Research Question}

What is the prevalence of psychological well-being among female married teachers and bankers in Lagos State?

\subsection{Research Hypotheses}

I. Psychological well-being has no significant influence on the marital stability of female teachers and bankers in Lagos State.

II. There is no significant difference in the marital stability of bankers and teachers.

\section{LITERATURE REVIEW}

\subsection{The Concept of Marital Stability}

The term stability is the quality, state of being consistent, and firmly established. Marital stability is a concept that shows whether a marriage relationship stayed intact or not (Stanley, Amato, Johnson, \& Markman, 2006). Mitchel and Plauche (2016) defined marital stability as "remaining legally married without divorce, physical separation, or legal separation." Married couples achieve marital stability when they abide, work, and continuously support each other in a given task, interest, or a set goal. Dubose (2015) opines that if partners do not make a conscious effort to make their relationship successful, they may face the risk of being neglected. Therefore, a stable relationship is achieved by the positive contribution of both couples. The marital relationship's stability leads to a well-functioning and balanced family life, which consequently leads to a well-adjusted and progressive society (Echebe, 2010). Marital stability is different from but closely related to marital quality and marital satisfaction. Marital satisfaction leads to marital stability. It is a crucial part of family life and life satisfaction, and couples who have stable and fulfilled marriages are healthier, happier, and enjoy longevity (Whisman, Gilmour \& Salinger, 2018).

\subsection{The Concept of Psychological Well-Being}

The World Health Organization (WHO, 2019) describes good mental health as psychological well-being. It defines psychological well-being as a state where an individual can accomplish a task, cope with life's challenges, being productive at work, and contributes to the growth and development of one's community. The term psychological well-being is used synonymously with mental health. It is defined from the eudaimonic approach's philosophy, which defines psychological well-being as the optimal functioning of individual and social life (Huppert, 2017; Keyes et al., 2002). Ryff examined the meaning of psychological well-being and perceived that well-being would be more meaningful when broken into six dimensions, each of which contributes to people's experience of well-being. These include autonomy, environmental mastery, 
personal growth, positive relations with others, purpose in life, and self-acceptance. They are briefly explained as follows:

(1) Autonomy

Autonomy means the ability to be in control of one's behaviour. A fully functioning person can assess and evaluate his or her achievements and not depend on another people's judgment. He/she must be well behaved, make personal decisions, and not being carried away by other people's ideas.

(2) Personal Growth

Personal growth refers to the capacity to grow and develop oneself in various areas of human endeavours, be self-actualised, achieve a set goal, excel in one's field of career, and arrive at a point of being a productive, fully functioning person. Personal growth requires a continuous struggle to solve life's problems, leading to increased acquisition of skills and knowledge.

\section{(3) Environmental Mastery}

Environmental mastery is an individual's ability to manipulate one's environment through mental and physical activities (Ryff \& Keyes, 1995). A person who can control his or her situation, interact effectively with different people in different situations, adjust to other demands, and face life challenges is a psychologically healthy person.

(4) Purpose in Life

In this perspective, an individual who knows the reason for his or her existence set achievable goals and works towards the actualisation of this goal to live a meaningful and productive life is psychologically well. When somebody realises his purpose in life, he makes a self-directed effort and intentional moves to achieve the same goal. Having a purpose in life is critical for implied psychological well-being.

(5) Positive Relation with Others

Positive relationship with others is a crucial element in building a trusting and long-lasting relationship and, at the same time, getting involved in communication and support networks. When an individual can work with others, trust, love, care, calm and polite in his or her approaches, effective communication and interpersonal relationship with others are promoted.

(6) Self-acceptance

Self-acceptance is a basic form of mental health and the fundamental power of ideal functioning. It is the most common expression of psychological well-being. An individual who expresses self-acceptance is optimistic, generally happy, and satisfied with life (Ryff 1989). These six dimensions cover a broad level of wellness, summarized as the outright assessment of oneself, being determined, focused, having an excellent inter-personal relationship, emotional intelligence, having a sense of purpose, and meaningful life (Ryff, 1985).

\subsection{Psychological Well-Being and Marital Stability}

One of the crucial factors that promote marital stability is the couples' ability to know the state of their psychological health because poor psychological well-being reduces the chance of marital satisfaction (Ghazivakili, Norrouzinia, Kabir, \& Karimi (2014). In a study by Azimian, Piran, Jahanihashem, and Dehshankar (2017) on marital satisfaction and its relationship with job stress and health, 64\% of participants had marital satisfaction. The study also revealed that there is a significant relationship between marital satisfaction and psychological well-being. On the other hand, Mamun, Clavarino, Najman, Williams, Callaghan, and Bor (2009) found a strong bidirectional relationship between depression and matrimonial relationships among women. Women who reported depressive symptoms reported poor marital relationships, while those without depressive symptoms reported high-quality marital relationships.

Randall \& Bodenmann (2017) postulated that people who had poor psychological well-being experienced stressful situations and engaged in hostile conversations with their spouses, and this could lead to marital crisis, instability, and reduced psychological well-being. This is supported by Oginyi, Ofoke, and Francis (2015), who found a significant relationship between psychological well-being and marital stability. Similarly, Azimain, Piran, Jahanihashem, and Dehshankar (2017) found that depression $(p=0.012)$ and anxiety $(\mathrm{p}=0.001)$ had a significant relationship with marital satisfaction. On the contrary, Katagulle et al. (2017) reported no significant relationship between psychological well-being and marital satisfaction. In support of 
this finding is Kamp-Dush, Taylor, and Kroeger's (2008) study, which found that the respondents who had poor marital happiness had the highest psychological well-being level.

Yadav and Kumar's (2015) found that female banker, compared to the teachers, especially those in their early adulthood, experience more instability at home and poor psychological well-being, particularly in economically disadvantaged areas. Teachers were also found to have better mental health when compared to bankers. Similarly, Goel, Narang, and Koradia's (2013) study on marital adjustment and mental health among bank employees and doctors during middle age found no significant difference in the marriage adjustment and mental health of female bank workers and doctors. In the same viewpoint, Rashmi and Shafiq (2017) revealed no significant difference in the level of the mental health and marital adjustment of female married teachers and female married workers in other service-oriented organizations $t=0.58$.

\subsection{Prevalence of Psychological Well-being}

According to a report, the prevalence of poor psychological well-being is in the range of $20 \%$ (Mental Health Leadership and Advocacy Programme, 2012). It was also reported that 64 million Nigerians out of 174 million populations suffer one form of mental illness or the other (World Bank, 2013). Ibitoye, Sanuade, Adebowale, and Ayeni (2014) studied the psychological well-being of the elderly in Nigeria and found that more than half of the respondents $(53.3 \%)$ had poor psychological well-being. A more significant number of them were women $(65.20 \%)$, and $(71.3 \%)$ were married. Similarly, Ghayas, Shamim, Anjum, and Hussan's (2014) study found that the prevalence of depression was $(53.43 \%)$ for males and $(61 \%)$ for females. In the same vein, Bakare, Ibrahim, Isah, and Yunusa (2017) reported that $54,2 \%$ of participants were psychologically distressed, and $38.7 \%$ had low satisfaction with their psychological well-being. In a study by Velmuuruugan and Maheswari (2015), it was revealed that most of the women $(63.5 \%)$ had an average level of psychological well-being, $27.1 \%$ had a low level, while $9.4 \%$ had a high level of psychological well-being. Srimathi and Kumar (2010) found that women who worked in industries had lower psychological well-being. Bankers had moderate while women in the teaching profession had the highest score in psychological wellbeing. Molina, Fialho, Bach, Amaral, Rocha, and Souza's (2017) study found a high prevalence of psychological well-being among the teachers. Out of 575 teachers, $460(79.5 \%)$ experienced good psychological well-being. On the other hand, Pandey and Srivastava (2003) found that teachers had a moderate psychological well-being level than the bankers. In the same vein, Asa and Lasebikan (2016) conducted a study on teachers' mental health in Nigeria. They found that the prevalence of stress as determined by the teacher stress scale was 340 (72.2\%), depression $43(29.3 \%)$, generalised anxiety disorder $44(29.5 \%)$. A positive correlation was also seen between the teacher's stress, anxiety disorder, and depression $(p<0.001)$.

\section{METHODS}

This study employed a descriptive survey research design. The study population consists of married female employees in secondary schools and commercial banks in Lagos State who were estimated at 22,025. A sample size of 646 was obtained using the MaCorr research sample size calculator software, setting the criterion at a $99 \%$ confidence level and $5 \%$ confidence interval.

$\frac{S S=Z^{2} \times(P) \times(1-P)}{C^{2}}$

Where,

$\mathrm{Z}=\mathrm{Z}$ value (e.g., 2.54 for $99 \%$ confidence level)

$\mathrm{P}=$ percentage of picking a choice, expressed as decimal

(0.5 used for sample size needed)

$\mathrm{C}=$ confidence interval (margin of error), expressed as decimal

(e.g., $.0 .5= \pm 5$ )

Therefore, $\mathrm{SS}=\frac{2,54^{2} \times(0.5) \times(1-0.5)}{0.05^{2}}$

$=\underline{6.46 \times 0.5 \times 0.5}$

0.002

$=646$

The multi-stage sampling technique was adopted to select the respondents and the location of the study. Data was collected using a questionnaire structured in two sections. Section one measured the sociodemographic information of the research participants while the second section includes: the scale of Psychological Well-being (Ryff and Keyes, 1995) - an 18-item scale covering the six dimensions of wellbeing with 5 points Likert-type scale ranging from 5 (Strongly Agree) to 1 (Strongly Disagree) having its 
original reliability coefficient of $.81-.88$ and marital stability scale - a 25 item scale with a 5 point Likert-like scale having Cronbach Alpha of .912. The merging of total score arrived from the 18 and 25 items present the total score of psychological well-being and marital stability. Ethical standards were maintained in carrying out this study. The approval of the Covenant University Ethical Review Board was obtained. Before the data collection exercise was embarked upon, informed consent was sought and obtained from the participants after obtaining permission from their organizations' top management. The participants were assured of anonymity and confidentiality. The completed questionnaires were collected from the participants, sorted, coded and analysed. Descriptive statistics such as simple frequency count and percentages were used to answers the research question. The hypotheses were tested using simple linear regression and independent sample t-test. Out of the 646-questionnaire administered to the research participants, 540 were deemed fit for data analyses, accounting for an $83 \%$ response rate.

\section{RESULTS}

\subsection{Demographic Data}

This section shows the descriptive statistics of the participants of the study. This information is expressed in frequencies and percentages.

Table 1: Socio-Demographic Characteristics of Participants in the study $(n=540)$

\begin{tabular}{|l|c|l|l|l|l|}
\hline \multicolumn{2}{|l|}{ Teachers } & \multicolumn{2}{l|}{ Bankers } & \\
\hline Demographics & Frequency & Percentages & Frequency & Percentages & Total \\
\hline Education & & & & & \\
\hline ND/NCE & 49 & 9.1 & 40 & 7.4 & $89(16.5 \%)$ \\
\hline & & & & & \\
\hline Bsc/ BA/HND & 198 & 36.7 & 168 & 31.1 & $366(67.8 \%)$ \\
\hline Higher Degrees & 44 & 8.1 & 41 & 7.6 & $85(15.7 \%)$ \\
\hline Total & 291 & 53.9 & 249 & 46.1 & $540(100 \%)$ \\
\hline Year of Marriage & & & & & \\
\hline $1-3$ & 17 & 3.2 & 86 & 15.9 & $103(19.1 \%)$ \\
\hline $4-6$ & 41 & 7.6 & 69 & 12.8 & $110(20.4 \%)$ \\
\hline $7-9$ & 32 & 5.9 & 41 & 7.6 & $73(13.5 \%)$ \\
\hline 10 Above & 201 & 37.2 & 53 & 9.8 & $254(47 \%)$ \\
\hline Total & 291 & 53.9 & 249 & 46.1 & $540(100 \%)$ \\
\hline Year in Organisation & & & & & \\
\hline $1-10$ & 131 & 24.3 & 208 & 38.5 & $339(62.8 \%)$ \\
\hline $11-20$ & 107 & 19.8 & 40 & 7.4 & $147(27.2)$ \\
\hline $21-30$ & 48 & 8.9 & 1 & 0.2 & $49(9.1)$ \\
\hline 31 Above & 5 & 0.9 & NONE & 0 & $5(0,9)$ \\
\hline Total & 291 & 53.9 & 249 & 46.1 & $540(100)$ \\
\hline Age & & & & & \\
\hline $23-32$ & & & & & \\
\hline $33-42$ & 23 & 4.3 & 116 & 21.5 & $139(25.7 \%)$ \\
\hline $43-52$ & 91 & 16.8 & 107 & 19.8 & $198(36.7 \%)$ \\
\hline 53 Above & 128 & 23.7 & 23 & 4.3 & $151(28.0 \%)$ \\
\hline Total & 49 & 9.1 & 3 & 0.5 & $52(9.6 \%)$ \\
\hline
\end{tabular}

Source: Survey data, 2019

Table 1 shows the demographic characteristics of the participants by occupation (teachers and bankers). Distribution revealed that $53.9 \%$ were teachers, while $46.1 \%$ were bankers. In the Educational qualification distribution of teachers, $9.1 \%$ were NCE/ND holders, $36.7 \%$ had B.Sc/BA/B.Ed./HND while those that had higher degrees were $8.1 \%$. For the bankers, 7.4 were NCE/ND holders, $31.1 \%$ had B.Sc/BA/B.Ed./HND while those that had higher degrees were $7.6 \%$. Considering the years of participants' marriage, teachers who had been married for over ten years were 37.2\%, 5.9 had been married for between seven and nine years, $7.6 \%$ between four and six years, and 3.2\% married between 1 to three years. For the bankers, $9.8 \%$ 
had been married for over ten years, $7.6 \%$ had been married for between seven and nine years, $12.8 \%$ between four and six years and $15.9 \%$ were married between 1 to three years. Teachers who had been in their current organizations for less than ten years constitute 24.3\%, those between 11 to 20 years were $19.8 \%$, those who had spent between 21 years to 30 years constitute $8.9 \%$, while those who had spent over 30 years constitute $0.9 \%$. Considering the number of years bankers have spent in their organization, $38.5 \%$ had spent less than ten years, those between 11 to 20 years were $7.4 \%, 0.2$ had spent between 21 years to 30 years, while those who had spent over 30 years constitute $0 \%$. The age distribution of teachers revealed that $4.3 \%$ were between 23 and 32 years, $16.8 \%$ were 33 and 42 years, $23.7 \%$ were 43 and 52 years, $9.1 \%$ were 53 years, and above, while that of bankers showed that $21.5 \%$ were between 23 and 32 years, $19.8 \%$ were 33 and 42 years, $4.3 \%$ were 43 and 52 years, and 0.5 were 53 years above.

\subsection{Research Question}

What is the prevalence of psychological well-being among female teachers and bankers in Lagos State?

Table 2: Prevalence of Psychological Well-being among women in Lagos State.

\begin{tabular}{|c|c|c|}
\hline $\begin{array}{c}\text { Psychological well- } \\
\text { being }\end{array}$ & Frequency (F) & Percentage (\%) \\
\hline High & 535 & 99.1 \\
\hline Low & 5 & 0.9 \\
\hline Total & 540 & $\mathbf{1 0 0}$ \\
\hline
\end{tabular}

The result shows that $535(99.1 \%)$ out of 540 respondents score high on the psychological well-being scale, and $5(0.9 \%)$ score low. It indicates that most women had good psychological well-being, accounting for a high prevalence of psychological well-being.

\subsection{Research Hypotheses}

Hypothesis One states that there is no significant influence of psychological well-being on women's marital stability in Lagos State.

Table 3: Regression showing Influence of Psychological Well-Being on Marital Stability

\begin{tabular}{|c|c|c|c|c|c|c|}
\hline \multirow{2}{*}{\multicolumn{2}{|c|}{ Selected Variables }} & \multicolumn{2}{|c|}{$\begin{array}{l}\text { Unstandardized } \\
\text { Coefficients }\end{array}$} & \multirow{2}{*}{$\begin{array}{c}\begin{array}{c}\text { Standardized } \\
\text { Coefficients }\end{array} \\
\text { Beta }\end{array}$} & \multirow[b]{2}{*}{$\mathrm{T}$} & \multirow[b]{2}{*}{ Sig. } \\
\hline & & B & Std. Error & & & \\
\hline \multirow[t]{7}{*}{1} & (Constant) & 53.538 & 3.222 & & 16.618 & .000 \\
\hline & Autonomy & .350 & .229 & .077 & 1.529 & .127 \\
\hline & Environmental Mastery & -.408 & 240 & -.086 & -1.702 & .089 \\
\hline & Personal Growth & .249 & .252 & .048 & .989 & .323 \\
\hline & Positive Relation & -.549 & .224 & -.134 & -2.449 & .015 \\
\hline & Purpose in Life & -.256 & .234 & -.058 & -1.093 & .275 \\
\hline & Self-Acceptance & .324 & .260 & .065 & 1.247 & .213 \\
\hline
\end{tabular}

The finding revealed that psychological well-being significantly influences women's marital stability at $R=.184, R^{2}=0.034, F=3.104, p=0.005$. 
Hypothesis Four: There is no significant difference in the marital stability of teachers and bankers.

Table 4: Independent Sample t-test showing the Difference in the Marital Stability of Teachers and Bankers in Lagos State.

\begin{tabular}{|c|c|c|c|c|c|c|c|c|}
\hline Variable & Group & $\mathbf{N}$ & Mean & SD & SE & T & Df & P \\
\hline & Teachers & 291 & 52.531 & 9.336 & .54730 & & & \\
\hline Marital Stability & & & & & & 2.751 & 538 & 0.03 \\
\hline & Bankers & 249 & 50.261 & 9.889 & .62671 & & & \\
\hline
\end{tabular}

The independent sample t-test revealed no significant difference in the marital stability of female married teachers and bankers at $(\{t(538)=2.751, d f=538 ; p=0.030)$.

\section{DISCUSSION}

The research question shows that out of 540 participants, 535 (99.1\%) have high psychological well-being, while $5(0.9 \%)$ have low psychological well-being. This implies a high prevalence of psychological well-being. This present finding agrees with Molina, Fialho, Bach, Amaral, Rocha and Souza (2017), who reported a high prevalence of psychological well-being among teachers. The study revealed that out of 575 teachers, $460(80 \%)$ experienced psychological well-being. In a similar survey by Srimathi and Kumar (2010), it was reported that women in the teaching profession showed the highest score in psychological well-being, followed by bankers who had moderate scores and women in industries who had lower psychological wellbeing scores. On the contrary, Bakare, Ibrahim, Isah and Yunusa (2017) reported that $54.2 \%$ of the study participants were psychologically distressed, and $38.7 \%$ had low satisfaction with their psychological wellbeing. Similarly, Somoye, Babalola and Adebowale (2015) showed the prevalence of anxiety disorder and major depressive symptoms among the bankers in southwest Nigeria. The first hypothesis tested using linear regression analysis was rejected $\left(R=.184, R^{2}=0.034, F=3.104, p=0.005\right)$. The results show that the combination of the six dimensions of psychological well-being influences marital stability. The finding agrees with earlier studies. For example, Roslan, Ahmad, Nabilla and Ghiami (2017) found a high psychological well-being level among the participants. Khajeh, Goodarzi and Soleiman (2014) found a significant correlation between psychological well-being and marital stability. However, this result is not consistent with Karagulle et al. (2019), who found that psychological well-being had no significant relationship with marital satisfaction. The second hypothesis, which was tested using the independent sample t-test, was accepted $\{t$ $(538)=2.751, p>.05$. It implies that teachers and bankers do not significantly differ in their marital stability. The study's result agrees with Sinha (2016) and found no significant difference between the marital adjustment of college teachers and school teachers but contradicts Yadav and Kumar (2015) reported that female bankers experienced higher marital instability to the teachers.

\section{CONCLUSION AND RECOMMENDATION}

The study concluded that positive relations with others as an indicator of psychological well-being is positively related to marital stability. Psychological well-being and family life programmes should be incorporated into organizations' policies through counselling interventions to improve women's well-being, marital life, and job satisfaction in Lagos State. Similarities in participants' marital stability could be explained by different coping strategies, which the women in the two sub-sectors had devised to manage their work roles and family responsibilities.

\section{ACKNOWLEDGEMENTS}

The authors appreciate the Covenant University Centre for Research, Innovation and Discovery (CUCRID), that provided funding for the publication of this paper. 


\section{REFERENCE LIST}

Adejori, T. A., Okolie, B. O., Musa, T., Shehu, N. \& Dalhutu, H. (2019). Marital satisfaction and stability Efficacyof counselling. International Journal of Research and Innovations in Social Sciences, vol. 2.

Amina, R. N. (2008). Marital instability and its impact on women and children in Bangladesh. Shahid Sharawardi College Laxmibazar, Dhaka, Bangladesh.

Asa, F. T., \& Lasebikan, V. O. (2016). The mental health of teachers: Teachers' stress, anxiety, and depression among secondary schools in Nigeria. International Neuropsychiatric Disease Journal, vol. 4.

Azimian, J., Piran, P., Jahanihashem, H \& Dehshankar, L. (2017). Investigation of marital satisfaction and its relationship with job stress and general health of nurses in Qazvin, Iran.

Bakare, A.T., Ibrahim, M.T.O., Isah, B.A., \& Yunusa, M. A. (2017). Mental health and well-being among health workers in selected health facilities in Sokoto Metropolis, Sokoto State, Nigeria. Journal of Psychiatry and Cognitive Behaviour, 2, 110. Doi:1029011/2574-7762.00010.

Comez-Ikican, T., Cosansu, G., Erdogan, G. et al. (2020). The relationship of marital adjustment and sexual satisfaction with depressive symptoms in women. Sexuality and Disability, vol. 38. https://doi.org/10.1007/s111995-019-09590-7.

Cummings E. M., Merrilees C. E., George M. (2010). Fathers, marriages and families: Revisiting and updating the framework for fathering in family context. In: Lamb M, editor. The Role of the Father in Child Development. Fifth Edition. NY: John Wiley \& Sons;154-176.

DuBose, M. (2015). Why do people divorce? www.mikedubose.com.

Eaton, D. K., Kann, L, Kinchen, S. Shanklin, S. Flint, K. H., \& Hawkince, J (2012). Youth risk behaviour surveillance - United State, 2011, Surveillance Summaries, vol. 4

Echebe, P. I, (2010). Family Psychology, Port Harcourt: University of Port-Harcourt Press.

Ghayas, S., Shamim, S., Anjum, F., \& Hassan, M. (2014). Prevalence and severity of depression among undergraduate students in Karachi, Pakistan: A cross sectional study. Tropical Journal of Phamaceutial Research, vol. 10.

Ghazivakili, Z., Norouzinia, R., Kabir, K., \& Karimi, M. (2014). The mental health of people who are going to marry

and its relation to some of their demographic factors. Alborg University of Medical Sciences, vol. 3.

Goel, S., Narang, D., \& Koradia, K. (2013). Marital adjustment and mental health among bank employees and doctors during middle age in Delhi. International Journal of Science and Research Publications, vol. 1.

Hazarika, J. (2019). What are the functions of marriage? Toppr Ash Programme.

Huppert, F. (2017). Challenges in defining and measuring well-being and their implication for policy In book: Future Directions in Well-Being (pp.163-167). DOI: 10.1007/978-3-319-56889-8_28

Ibitoye, O. Sanuade, O. Adebowale, A. \& Ayeni, O. (2014). Psychological well-being of elderly in Nigeria. The Nigerian Journal of Sociology and Anthropology, vol.1.

Kamp-Dush, C. M., Taylor, M. G., \& Kroeger, R. A. (2008). Marital happiness and psychological well-being across the life course. Family Relations, 57, 211-226. doi:10.1111/j.1741-3729.2008. 00495.x

Kamp-Dush, C. M., Rhoades, G. K., Sandberge-Thoma, S. E., \& Shoppe-Sullivan, S. J. (2014). Commitment across the transition to parenthood among married and cohabiting couples. Couple Family Psychology, vol. 2.

Karagulle, O. O., Yavuz, E., Gulcicek, O. B., Solmaz, A., Senturk, S., Erdogan, A., Celik, A., \& Celebi, F. (2019). Psychological well-being and marital satisfaction in response to weight loss after bariatric surgery. Surgery Today, vol. 5. https://doi.org/10.1007/s00595-018-1750-8. 
Karney, B. R. \& Bradbury, T. N. (2020). Research on marital satisfaction and stability in the 2010s: Challenging convention wisdom. Journal of Marriage and Family, vol. 1.

Keyes, C. L. D., Shmotkin, D., \& Ryff, C. D. (2002). Optimizing well -being. The empirical encounter of two traditions. Journal of Personality and Social Psychology, vol. 82.

Khaijeh, A., Goodarzi, M., \& Soleiman, F. (2014). The relationship of psychological well-being with marital quality and the dimensions of the married students. India Journal of Science Resources, vol. 1,

Kolappa, K., Henderson, D. C., \& Kishore, S. P. (2013). No physical health without mental health: MaCorr, (2003-2018). MaCorr research solution online available at http/www.macorr.com/sample.size.calculator.htm

Mamun, A. A., Clavarino, A. M., Najman, J. M., Williams, G. M. O'Callaghan, M. J., \& Bor, W. (2009). Maternal depression and the quality of marital relationship: A 14-year prospective study. Journal of Women's Health (Larchmt), vol. 12.

Mental Health Leadership and Advocacy Programme (2012). Mental health situation analysis in Nigerian.

College of Medicine, University of Ibadan.

Mitchel, K. S., \& Plauche, H. (2016). Marital stability. The Wiley Blackwell Encyclopedia of Family Studies. 1-

2. Retrieved from htts;//onlinelibrary.wiley.com/doi/10.1002/19781119085621.wbefs276

Molina, M.L., Fialho, A. R., Amaral, P.,Rocha, L. M., \& Souza, L.D.M. (2017). Well-being and associated

factors among elementary school teachers in Southern Brazil. Rev. CEFAC, 19, 6. https: doi.org//100159/1982-021620171462217.

Nadar, N. (2018). Workplace stress, marital adjustment and marital satisfaction. Indian Journal of Mental Health, vol. 4.

Oginyi, R. C. N., Ofoke, S.M., \& Francis, C. (2015). Religiosity, forgiveness, and psychological well-being as predictors of marital satisfaction among academic staff of Ebonyi State University, South Eastern, Nigeria. Journal

of Education Research and Behavioural Sciences, vol.12.

Pandey, S., \& Srivastava, S. (2003). Work stress and coping as a predictor of the health status of career women. Journal of the Indian Academy of Applied Psychology, 29.

Randall, A. K. \& Bodenman, G. (2017). Stressand its association with relationship satisfaction. Current Opinion in Psychology, 13.

Rashmi, S., \& Shafiq, M. (2017). Mental health and marital adjustment of working women. International Journal of All Research Educational and Scientific Methods, vol. 1.

Roslan, S., Ahmad, N., Nabilla, N., \& Ghiami, Z. (2017). Psychological well-being among postgraduate students.

Acta Medical Bulgarica, vol. 1.

Ryff, C. D (1985). Adult personality development and the motivation for personal growth. In D. Kleiber and M. Machr (Eds.) Advances in Motivation and Achievement, 4. Motivation and adulthood. (pp. 55-92). Greenwich, CT. JAI Press.

Ryff, C. D. (1995). Psychological well-being in adult life. Retrieved from http://doi.org/10.1111/14698721.ep10772395

Ryff, C.D. \& Keyes, C. L. (1995). The structure of psychological well-being revisited, Journal of Personal Social Psychology, vol. 7.

Shakarami, M., Zahrakar, K., \& Mohsenzadeh, F. (2016). Determine the contribution of conflict resolution styles in predicting marital commitment. Journal of Research and Health, vol.4.

Shmerling, (2016). The health advantage of marriage. Harvard Health Psychology, Harvard Medical School. 
Sinha, S. (2017). Multiple roles of working women and psychological well-being. Industrial psychiatry Journal, vol. 2.

Somoye, E. B., Babalola, E. L. \& Adebowale, T. O. (2015). Prevalence and risk factors for anxiety and depression among commercial bank workers in Abeokuta, south western Nigeria. Journal of Behavioural Health, www.scopemed.org

Srimathi, N. L., \& Kumar, S. K. (2010). Psychological well-being of employed women across different organizations. Journal of the India Academic of Applied Psychology, vol. 1.

Stanley, S. M., Amato, P. R., Johnson, C.A., \& Markman, H. J. (2006). Premarital education, marital quality, and marital stability: Findings from a large, random household survey. Journal of Family Psychology, vol.1.

Velmurugan, K. S., \& Maheswari, D. K. (2015). A study on marital satisfaction of women working in Southern Railways Tiruchirappalli, International Journal of Scientific and Management, vol.10.

Whisman, M. A., Gilmour, A. L.\& Salinger, J. M. (2018). Marital satisfaction and mortality in the United States adult population, Health Psychology, vol. 11.

Whiteford HA, Degenhardt L, Rehm J, Baxter AJ, Ferrari AJ, Erskine HE, et al. (2013). Global burden of

Idisease attributable to mental and substance use disorders: findings from the global burden of disease study 2010. Lancet, vol. 9904.

World Health Oranisation (2019) (WHO). 10 facts on mental health.

World Health Oranisation (2020). Gender and women's mental health. Mental health action plan, 2013-2020.

Yadav, S., \& Kumar, R. (2015). Household stress and marital health among female teachers and family stress in Chinese working women: A validation study focusing on blood pressure and psychosomatic symptoms. Women Health, vol. 2. 